\title{
When Serendipity Knocks on the Door: Synthesis and Physicochemical Characterization of 7-Chloro-2,3-dihydro-5 $\mathrm{H}$-thiazolo[3,2-a]pyrimidin-5-one
}

\author{
Christian C. Carmona-Vargas, ${ }^{\circledR a}$ Javier Ellena, ${ }^{\circledR b}$ Richard F. D’Vries ${ }^{\circledR *, c}$ and \\ Manuel N. Chaur ${ }^{\circledR * a}$ \\ ${ }^{a}$ Departamento de Química, Facultad de Ciencias Naturales y Exactas, Universidad del Valle, \\ AA 25360 Cali, Colombia \\ ${ }^{b}$ Instituto de Física de São Carlos, Universidade de São Paulo, 13566-590 São Carlos-SP, Brazil \\ ${ }^{c}$ Facultad de Ciencias Básicas, Universidad Santiago de Cali, Cali, Colombia
}

\begin{abstract}
Herein, we present the serendipitous obtaining of 7-chloro-2,3-dihydro-5 $\mathrm{H}$-thiazolo [3,2-a]pyrimidin-5-one in $40 \%$ yield by using $\mathrm{POCl}_{3}$ and a thiobarbituric acid derivative. The thiazolopyrimidine derivative was characterized by ${ }^{1} \mathrm{H}$ nuclear magnetic resonance (NMR), UV-Vis, and Fourier transform infrared (FTIR) spectroscopy. Additionally, the structure was confirmed by single crystal X-ray diffraction, where it was found that the compound crystallizes in the P-1 triclinic space group with two conformeric molecules of 7-chloro-2,3-dihydro-5 $\mathrm{H}$-thiazolo $[3,2-a]$ pyrimidin-5-one by asymmetric unit. Also, from the structural data was studied the supramolecular interactions using Hirshfeld surface analysis and 2D fingerprint plots.
\end{abstract}

Keywords: chlorination, serendipity, thiazolopyrimidine, thiobarbituric acid

\section{Introduction}

Nowadays, chemists have more knowledge about molecular structure and reactivity of organic molecules, allowing them to plan synthetic routes in order to obtain a specific target. However, sometimes serendipity comes out to remember us that the misunderstanding of any detail in organic synthesis can ruin everything, or on the contrary, can lead to the formation of an unexpected product. Serendipity has led to important breakthroughs in chemical sciences, for instance, the discovery of the pigments Prussian Blue ${ }^{1}$ and mauveine, ${ }^{2}$ or the electrically conductive polymers obtained by the misunderstanding of one instruction in a routine synthesis, for which the 2000 Nobel Prize in chemistry was awarded. ${ }^{3,4}$

Serendipity in organic chemistry has been present in the discovery of new chemical processes and methodologies used for the construction of complex heterocyclic compounds. For example, Baran and co-workers ${ }^{5}$ developed a useful protocol for the synthesis of natural product-like heterocycles relevant to chemical biology and medicinal chemistry based on a two step reaction between anilides

*e-mail: richard.dvries00@usc.edu.co; manuel.chaur@correounivalle.edu.co and the Dess-Martin reagent. Another case of serendipity was reported by Basso et al. ${ }^{6}$ when attempting to perform a Passerini reaction, and stumbled upon the unprecedented condensation of arylacetic acids and isocyanides that produced two novel classes of polysubstituted pyrrolones and pyrrolidinediones. In the field of photochemical reactions, MacMillan and co-workers ${ }^{7}$ discovered a new reaction of $\mathrm{C}-\mathrm{H}$ functionalization of arenes (aryl amination) using ligand-free nickel(II) salts in a photoredox-catalyzed electron-transfer event.

In the same way, serendipity knocked on the door of our research. We were looking for the chlorination of a molecule containing two units of thiobarbituric acid linked by a triethylene glycol moiety through an $S$-alkylation using phosphoryl chloride. However, instead of obtaining the product of the nucleophilic aromatic substitution, the reaction went for another one, obtaining the product from the cleavage of the $\mathrm{C}-\mathrm{O}$ bond of the polyether chain, affording 7-chloro-2,3-dihydro-5 $H$-thiazolo [3,2-a]pyrimidin-5-one.

One finds with a bird's eye view of the literature that systems containing fused thiazole and pyrimidine rings like thiazolo[3,2-a]pyrimidines have attracted great attention due to their wide application in medicinal chemistry, 
because of their synthetic and pharmacological potential use in the search for new biologically active substances that allow the creation of more effective and safe drugs. Compounds containing the thiazolopyrimidine framework have been used in the synthesis of more complex molecules with several biological activities such as antifungal, ${ }^{8}$ antimalarial, ${ }^{9}$ antihypertensive, ${ }^{10}$ anti-inflammatory, ${ }^{11}$ antimicrobial, ${ }^{12}$ antiviral, ${ }^{13}$ and anticancer, ${ }^{14}$ among others.

Therefore, we envision that our compound could serve as a template for the development of novel compounds containing the thiazolopyrimidine core, due to the possibility for the functionalization of the pyrimidine ring through the substitution of the chlorine atom..${ }^{15}$ To the best of our knowledge, there is no more than one report in the literature about the synthesis of this mono-chlorinated compound. ${ }^{16}$ Therefore, herein we present a novel way to obtain this thiazolo[3,2-a]pyrimidine as well as a detailed study of its non-reported structural features.

\section{Results and Discussion}

In order to prepare the dimer of the thiobarbituric acid $\mathbf{3}$, it was necessary to synthesize the alkylating agent $\mathbf{2}$ (Scheme 1). First, triethyleneglycol reacted with $p$-toluene sulfonyl chloride ( $p$-TsCl) affording compound $\mathbf{1}$, which was subjected to reaction with sodium iodide to obtain the dihalogenated glycol $\mathbf{2}$. Then, it was carried out the alkylation of a twofold molar amount of thiobarbituric acid using compound $\mathbf{2}$ yielding the dimer $\mathbf{3}$ in 70\% yield (see Figures S1 and S2, Supplementary Information (SI) section).

In an attempt to chlorinate this dimer with phosphoryl chloride $\left(\mathrm{POCl}_{3}\right)$, we stumbled upon the surprise that the reaction took another pathway, producing the compound 4 . The proposed reaction mechanism for the formation of this compound (Scheme 2) involves the nucleophilic substitution of the phosphoryl group by a chlorine atom.

Initially, the hydroxyl group performs a nucleophilic attack on the phosphorus atom leading to the release of a chloride ion that carries out the nucleophilic substitution over the pyrimidine ring, generating a phosphoric acid derivative. Then, the strong acid, formed in situ, protonates the oxygen atoms of the polyether chain boosting the nucleophilic attack of the nitrogen adjacent to the carbonyl<smiles>Cc1ccc(S(=O)(=O)OCCOCCOCCOS(=O)(=O)c2ccc(C)cc2)cc1</smiles>

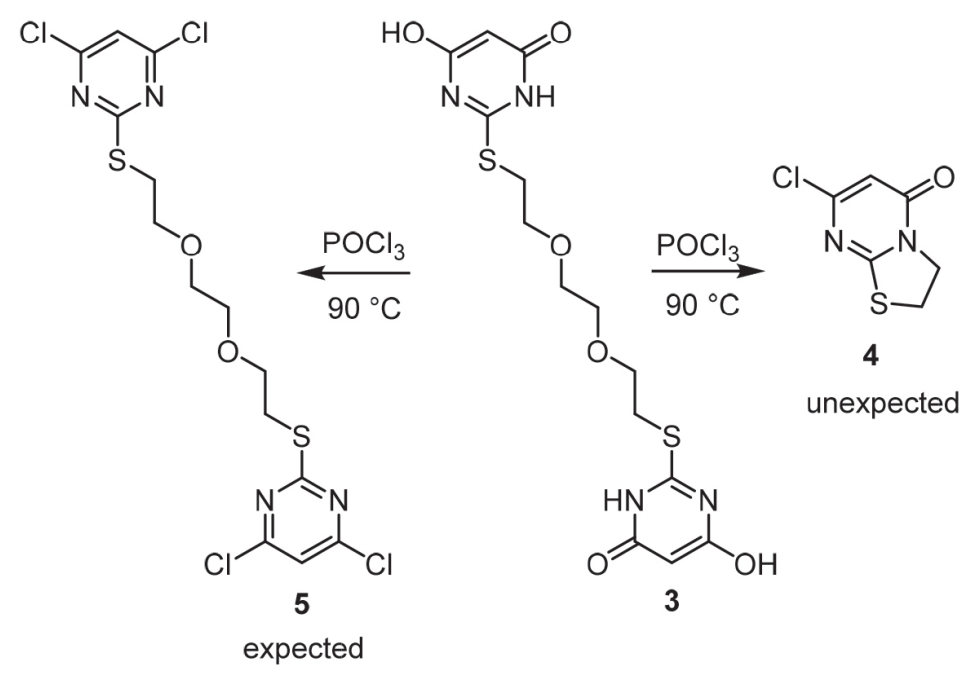

Scheme 1. Synthetic route for the synthesis of compound 4. 


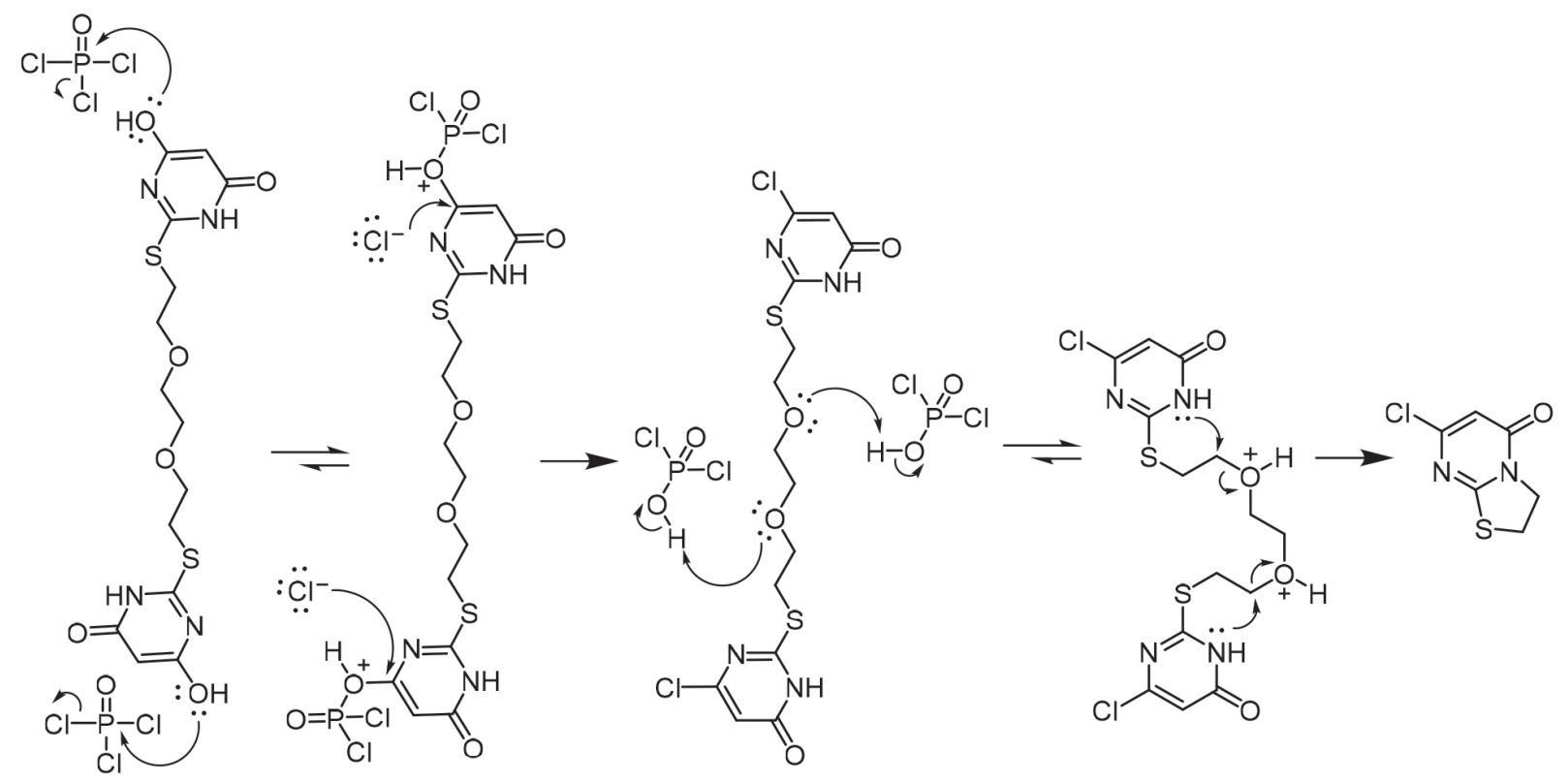

Scheme 2. Proposed mechanism for the formation of the thiazolopyrimidine 4.

group of the ring, which generates the cleavage of the $\mathrm{C}-\mathrm{O}$ bond of the polyether chain, affording the compound 4 . The ${ }^{1} \mathrm{H}$ and ${ }^{13} \mathrm{C}$ nuclear magnetic resonance (NMR) spectra of this compound exhibited all expected signals with the correct integration ratios (see Figures 1 and S3 (SI section), respectively). On the other hand, it was not possible to obtain the compound $\mathbf{5}$ under the reaction conditions that we explored using $\mathrm{POCl}_{3}$ as chlorinating agent.

Light yellow crystals of compound $\mathbf{4}$ were obtained by slow evaporation in ethyl acetate. The crystalline asymmetric unit is shown in Figure 2 and crystallographic and refinement details are presented in Table 1.

From the single crystal X-ray analysis it was possible to observe that compound $\mathbf{4}$ crystallizes in the $\mathrm{P}-1$ triclinic space group with two molecules crystallographically independent by asymmetric unit (see Figure 2). Both molecules in the asymmetric unit present differences in the torsion angle around the thiazole ring with values of 24.70(4) and $15.27(6)^{\circ}$ for $\mathrm{N} 1-\mathrm{C} 2-\mathrm{C} 1-\mathrm{S} 1$ and $\mathrm{N} 3-\mathrm{C} 8-\mathrm{C} 7-\mathrm{S} 2$, respectively. A comparison of superimposed conformers shows values of root-mean-square deviation (RMSD) of 0.0415 , indicating a small deviation of the atomic positions in both molecules (Figure 3).

From a supramolecular point of view, the conformers of the compound $\mathbf{4}$ present weak $\mathrm{C} 1-\mathrm{H} 1 \mathrm{~B} \cdots \mathrm{O} 2$ interactions with a distance of 3.043(4) $\AA$. The formed dimers are linked by weak $\mathrm{C} 11-\mathrm{H} 11 \cdots \mathrm{O} 1$ and $\mathrm{C} 8-\mathrm{H} 8 \mathrm{~B} \cdots \mathrm{Cl} 2$ with distances 3.321(4) and 3.380(3) $\AA$ along [100] direction and C7-H7B ‥N2 3.312(4) Å along [001] direction. These interactions give rise to supramolecular layers in the

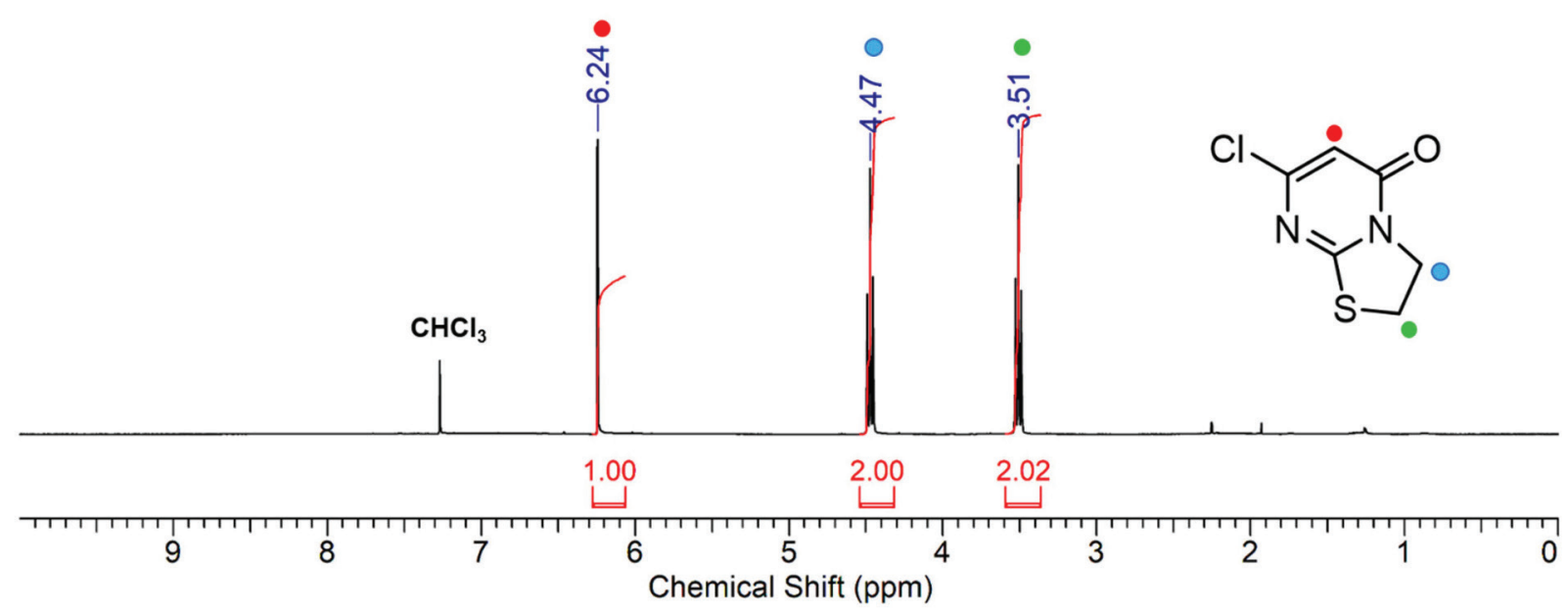

Figure 1. ${ }^{1} \mathrm{H}$ NMR spectrum of compound 4 in $\mathrm{CDCl}_{3}$. 

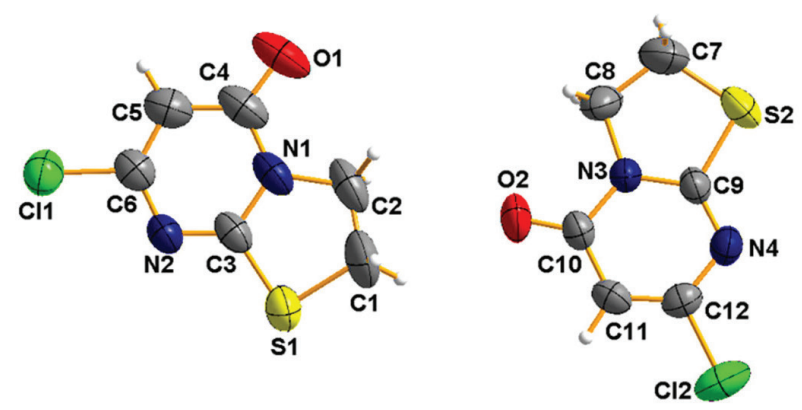

Figure 2. Oak Ridge thermal ellipsoid plot (ORTEP) representation of the asymmetric unit for the 7-chloro-2,3-dihydro-5 $\mathrm{H}$-thiazolo [3,2-a]pyrimidin-5-one (4) showing 50\% probability displacement ellipsoids.

Table 1. Crystallographic data and refinement parameters for the 7-chloro2,3-dihydro-5H-thiazolo[3,2-a]pyrimidin-5-one (4)

\begin{tabular}{|c|c|}
\hline Compound & $\begin{array}{c}\text { 7-Chloro-2,3-dihydro- } \\
5 H \text {-thiazolo[3,2- } a] \text { pyrimidin- } \\
\text { 5-one }\end{array}$ \\
\hline Empirical formula & $2\left(\mathrm{C}_{6} \mathrm{H}_{5} \mathrm{ON}_{2} \mathrm{SCl}\right)$ \\
\hline Formula weight / $\left(\mathrm{g} \mathrm{mol}^{-1}\right)$ & 377.26 \\
\hline Temperature / K & 293 \\
\hline Wavelength / $\AA$ & 1.54184 \\
\hline Crystal system & triclinic \\
\hline Space group & $\mathrm{P}-1$ \\
\hline \multicolumn{2}{|l|}{ Unit cell } \\
\hline$a / \AA$ & $8.977(4)$ \\
\hline$b / \AA$ & $9.276(5)$ \\
\hline$c / \AA$ & $9.512(3)$ \\
\hline$\alpha /$ degree & $88.12(2)$ \\
\hline$\beta /$ degree & $87.98(2)$ \\
\hline$\gamma /$ degree & $80.53(3)$ \\
\hline Volume / $\AA^{3}$ & $780.5(6)$ \\
\hline $\mathrm{Z}$ & 2 \\
\hline$\rho_{\text {cal }} /\left(\mathrm{mg} \mathrm{m}^{3}\right)$ & 1.605 \\
\hline Absorption coefficient $/ \mathrm{mm}^{-1}$ & 6.357 \\
\hline $\mathrm{F}(000)$ & 384 \\
\hline Theta range / degree & $4.7-66.5$ \\
\hline Reflections collected/unique [R(int)] & $10082 / 2644[0.033]$ \\
\hline Completeness / \% & 96.0 \\
\hline Data/restraints/parameters & $2644 / 0 / 200$ \\
\hline Goodness of fit on $\mathrm{F}^{2}$ & 1.06 \\
\hline $\mathrm{R}_{1}[\mathrm{I}>2 \sigma(\mathrm{I})]$ & 0.0383 \\
\hline $\mathrm{wR}_{2}[\mathrm{I}>2 \sigma(\mathrm{I})]$ & 0.1023 \\
\hline
\end{tabular}

plane (101). The layers are stacking among them along [010] direction via van der Waals interactions (Figure 4).

For a deep understanding of the crystal packing of the compound 4, Hirshfeld surface 2D fingerprint plots analysis ${ }^{17}$ were performed. These analyses give us more

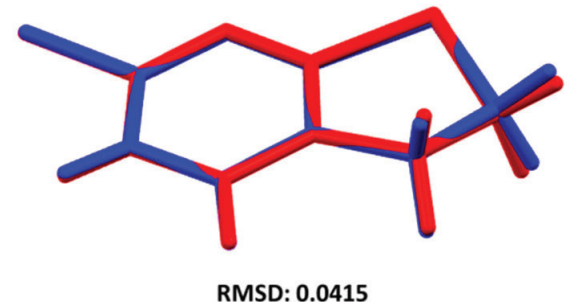

Figure 3. RMSD analysis by superimposing both conformers present in the asymmetric unit in the compound 4.

(a)

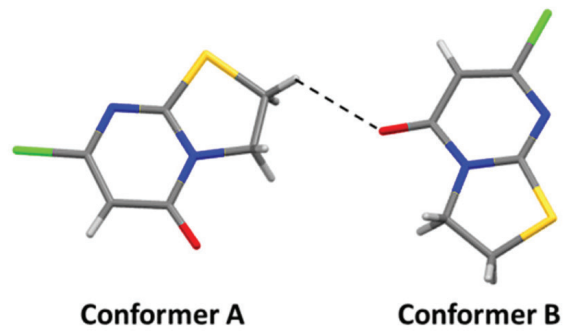

(b)
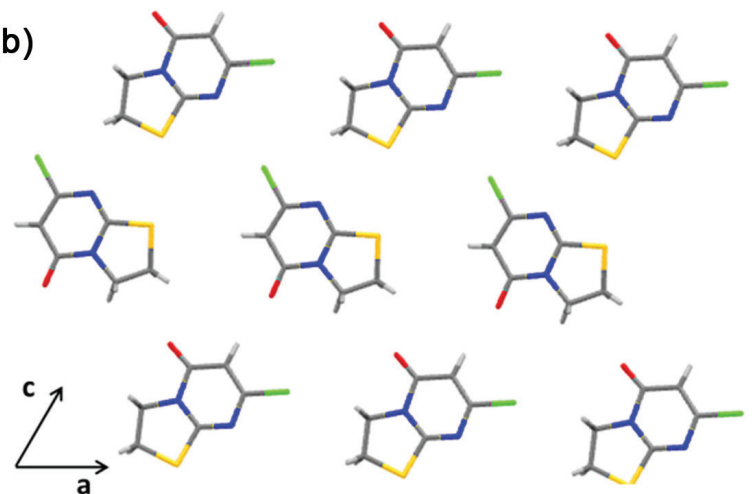

Figure 4. (a) Dimer formation by $\mathrm{C}-\mathrm{H} \cdots \mathrm{O}$ interactions and (b) layers in the (101) plane for the compound 4.

details about the interactions involved in the formation of the crystal packing. ${ }^{18-20}$ In the dnorm represented in Figure 5, it is possible to observe contacts shorter than the sum of the van der Waals radii in red, contacts close to their van der Waals limits in white, and the longest contacts in blue. For the dimeric units, present in the asymmetric unit, the red and white colors are positioned around the oxygen, chloride and sulfur atoms that act as acceptor atoms, and over the carbons that act as donor atoms. The 2D fingerprint plot shows that the most important interactions present are $\mathrm{O} \cdots \mathrm{H} / \mathrm{H} \cdots \mathrm{O}=11.3 \%, \mathrm{~N} \cdots \mathrm{H} / \mathrm{H} \cdots \mathrm{N}=10.3 \%, \mathrm{Cl} \cdots \mathrm{H} / \mathrm{H} \cdots \mathrm{Cl}$ $=21.4 \%, \mathrm{~S} \cdots \mathrm{S}=4.6 \%, \mathrm{H} \cdots \mathrm{H}=13.7 \%$ and $\mathrm{S} \cdots \mathrm{H} / \mathrm{H} \cdots \mathrm{S}=$ $9 \%$. These values are in agreement with the supramolecular interactions observed for this compound.

A search in the Cambridge Structural Database (CSD) shows 23 entries with functionalized thiazolopyrimidine core, and just one entry with an amino substitution in the 7 position of the thiazolopyrimidine. ${ }^{21}$ Structurally, both compounds present differences in the $\mathrm{N}-\mathrm{C}-\mathrm{C}-\mathrm{S}$ torsion 
(a)

(b)
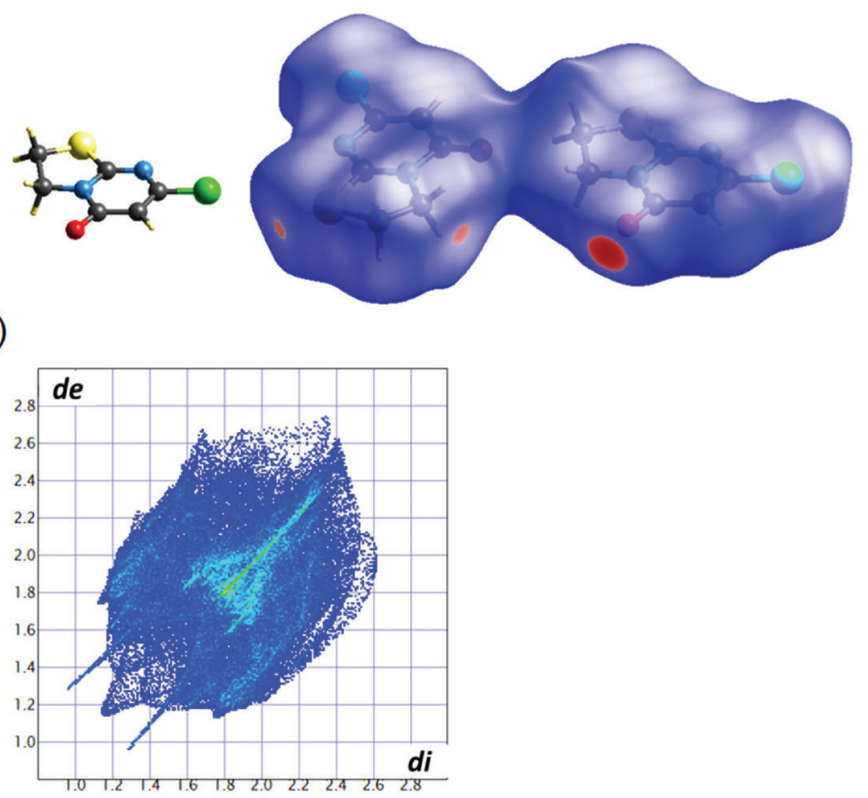

Figure 5. (a) dnorm Hirshfeld surface and molecular representation in the same orientation; and (b) 2D fingerprint plot for compound 4.

angle of $9.28(2)^{\circ}$, being a lower value than the conformers in the compound 4. Besides this, the supramolecular structure of the amino compound is based on $\mathrm{N}-\mathrm{H} \cdots \mathrm{O}$ interactions, due to the amino group present in the molecule (see Figure S4, SI section).

On the other hand, we carried out a UV-Vis analysis of compound $\mathbf{4}$ in solvents of different polarities, exhibiting a hyperchromic effect when the thiazolopyrimidine $\mathbf{4}$ was dissolved in a polar protic solvent as methanol. The absorption spectra show moderately intense bands in the $280-300 \mathrm{~nm}$ spectral region and a shoulder at $310 \mathrm{~nm}$. For this compound, $\pi-\pi^{*}$ transitions from the double bonds of the ring and $\mathrm{n}-\pi^{*}$ transitions from the lone pair electrons of the heteroatoms are expected, with the latter having lower extinction coefficients (Figure 6).

Cyclic voltammetry (CV) was used to characterize the redox behavior of compound $\mathbf{4}$, which featured a simple one-electron redox process showing an irreversible oxidation potential at $0.40 \mathrm{~V}$ (Figure 7). Also, compound 4 exhibits an irreversible reduction potential at $-1.50 \mathrm{~V}$. Both oxidation and reduction are irreversible and did not show any reversibility at higher scan rates. It is important to highlight that this is the first report on the electrochemical behavior of this thiazolopyrimidine in the literature.

\section{Conclusions}

7-Chloro-2,3-dihydro-5H-thiazolo[3,2- $a$ ]pyrimidin5 -one was obtained in a novel and unexpected manner from a new thiobarbituric derivative using $\mathrm{POCl}_{3}$ as chlorinating agent. The crystal structure analysis of compound $\mathbf{4}$ showed

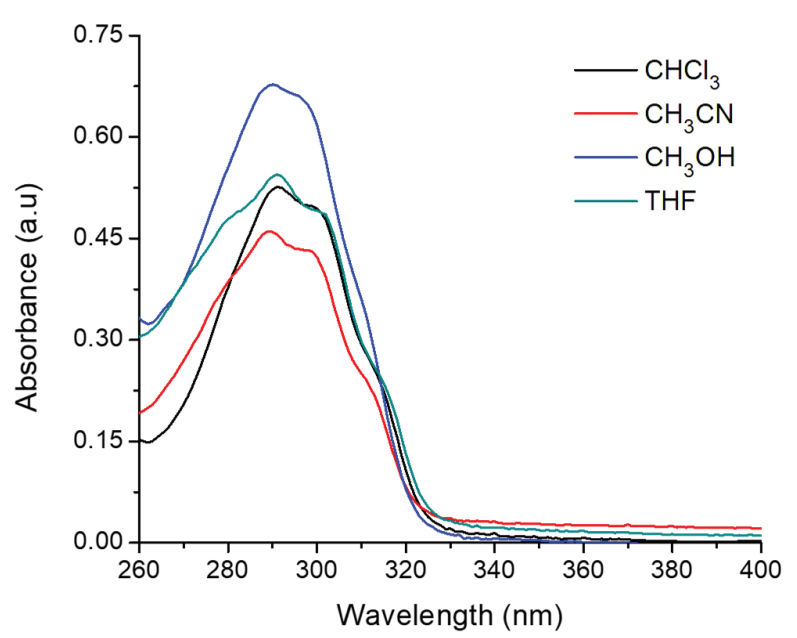

Figure 6. Absorption spectra of compound $\mathbf{4}$ in different solvents at $0.064 \mathrm{mM}$.

that the compound crystallizes in the P-1 triclinic space group, with two conformers by asymmetric unit. The supramolecular, Hirshfeld surface and fingerprint plots analysis reveal a supramolecular structure governed by $\mathrm{O} \cdots \mathrm{H}, \mathrm{N} \cdots \mathrm{H}$ and $\mathrm{S} \cdots \mathrm{H}$ interactions. Also, $\mathrm{Cl} \cdots \mathrm{H}$ interactions are present giving rise to the formation of layers in the (101) plane.

\section{Experimental}

\section{General information}

All chemicals were used as received from the commercial sources without further purification. For thin 

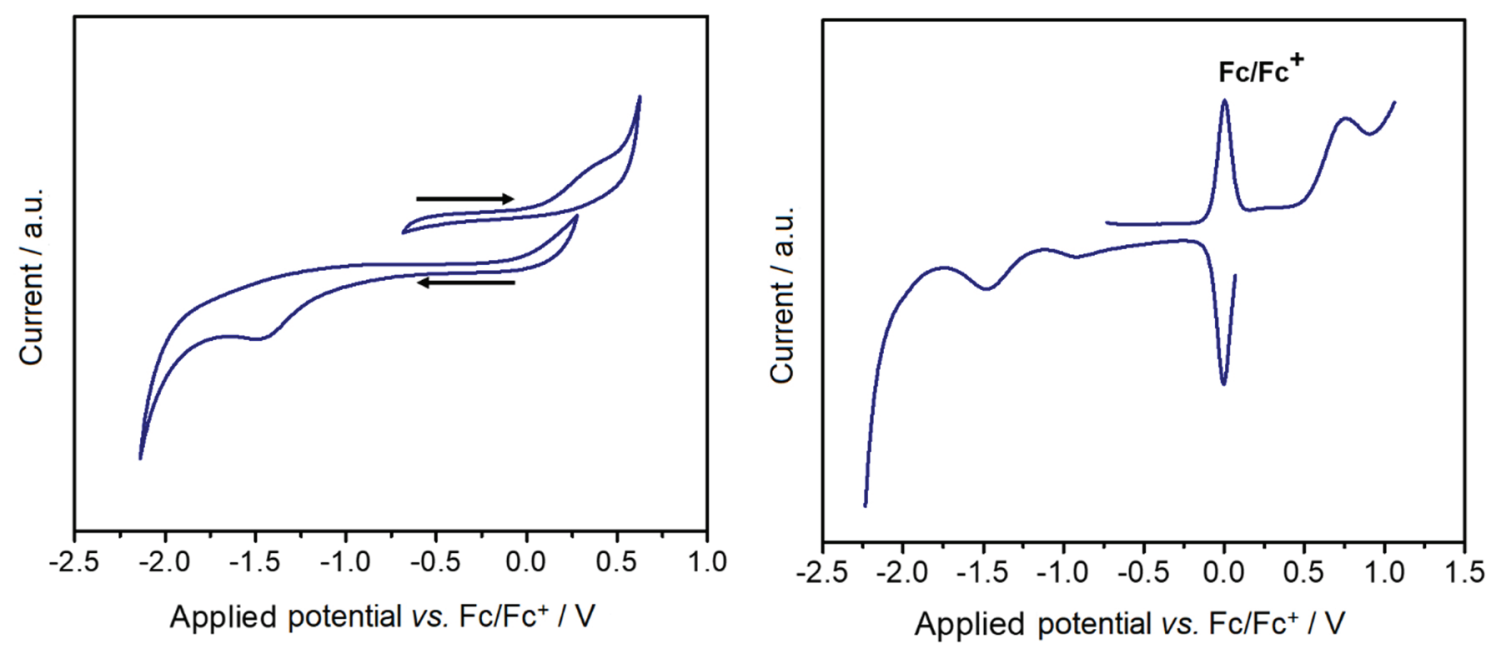

Figure 7. CV (left) and Osteryoung square wave voltammetry (OSWV; right) of compound 4 in tetrabutylammonium hexafluorophosphate $\left(\mathrm{NBu}_{4} \mathrm{PF}_{6}\right) / N, N$ dimethylformamide (DMF) with ferrocene as internal standard, $100 \mathrm{mV} \mathrm{s}^{-1}$ scan rate.

layer chromatography (TLC), 60 F254 $(0.25 \mathrm{~mm})$ silica gel was used to verify the purity of the products and to monitor the chemical reactions. A Spectroline E-Series lamp, with a wavelength of $363 \mathrm{~nm}$, and an iodine chamber was employed for visualization of TLC plates. Column chromatography (CC) was performed for the purification of the products, using 70-230 mesh silica gel particles.

\section{Synthesis}

Compound 1 was synthesized using the procedure previously reported in the literature, ${ }^{22}$ using a solution of triethylene glycol in dichloromethane at $0{ }^{\circ} \mathrm{C}$ with $p$-toluenesulfonyl chloride in the presence of triethylamine as base. Compound $\mathbf{2}$ was synthesized using a common procedure reported in the literature ${ }^{23}$ for the synthesis of iodoalkanes using sodium iodide in acetone at reflux.

\section{Synthesis of the alkylated thiobarbituric acid (3)}

Triethylamine $(0.5 \mathrm{~mL}, 3.55 \mathrm{mmol})$ was added to a solution of thiobarbituric acid $(0.495 \mathrm{~g}, 3.48 \mathrm{mmol})$ in methanol $(\mathrm{MeOH} ; 5.0 \mathrm{~mL})$ under stirring. Then, 1,2-bis(2-iodoethoxy)ethane (2) $(642 \mathrm{mg}, 1.74 \mathrm{mmol})$ was added to the mixture, and the resulting solution was refluxed for $7 \mathrm{~h}$ in an oil bath. The compound was precipitated using a solution of $0.1 \mathrm{M} \mathrm{HCl}$, filtered, washed with diethyl ether and dried at $50{ }^{\circ} \mathrm{C}$. Beige solid; yield: $70 \% ; \mathrm{mp}>100{ }^{\circ} \mathrm{C}$ (decomp.); infrared (IR) (attenuated total reflectance $($ ATR $)) \mathrm{v} / \mathrm{cm}^{-1} 3400(\mathrm{O}-\mathrm{H}), 3200(\mathrm{~N}-\mathrm{H})$, 2850-2650 (C-H), $1642(\mathrm{C}=\mathrm{O}), 1562(\mathrm{C}=\mathrm{C}), 1280(\mathrm{C}-\mathrm{O})$, $1230(\mathrm{C}-\mathrm{O}-\mathrm{C}) ;{ }^{1} \mathrm{H}$ NMR (400 MHz, dimethylsulfoxide (DMSO)- $d_{6}$ ) $\delta 11.97$ (s, very broad, $2 \mathrm{H}$ ), $5.17(\mathrm{~s}, 1 \mathrm{H}), 3.64$ (t, 4H), 3.57 (s, 4H), 3.29 (t, 4H); ${ }^{13} \mathrm{C}$ NMR (100 MHz, DMSO- $\left.d_{6}\right) \delta 86.1,70.1,69.4,29.7$; electron ionization- mass spectrometry (EI-MS) $(70 \mathrm{eV}) \mathrm{m} / z$ (\%) 401/402 $\left[\mathrm{M}^{+}\right](7 / 10)$; anal. calcd. for $\mathrm{C}_{14} \mathrm{H}_{18} \mathrm{~N}_{4} \mathrm{O}_{6} \mathrm{~S}_{2} .5 \mathrm{H}_{2} \mathrm{O}$ : C 34.14, H 5.73, N 11.39; found: C 33.75, H 5.67, N 10.69.

Synthesis of 7-chloro-2,3-dihydro-5H-thiazolo[3,2-a]pyrimidin5-one (4)

A solution of $\mathbf{3}(0.420 \mathrm{~g}, 1.04 \mathrm{mmol})$ in $\mathrm{POCl}_{3}(1.15 \mathrm{~mL}$, $12.4 \mathrm{mmol}$ ) was refluxed for $6 \mathrm{~h}$ in an oil bath under inert atmosphere. The resulting orange mixture was added to $8 \mathrm{~mL}$ of ice-cold water, and the liquid extraction procedure was repeated three times with $15 \mathrm{~mL}$ of ethyl acetate. The organic phase was washed with a saturated solution of sodium bicarbonate, dried with sodium sulfate, and the solvent was eliminated under reduced pressure. This compound was purified by $\mathrm{CC}$ using as eluent a mixture of hexane:ethyl acetate 20:1 to obtain a yellow solid (yield: $40 \%$ ). The slow evaporation of a solution of this compound in ethyl acetate afforded yellow crystals suitable for X-ray diffraction. mp $90{ }^{\circ} \mathrm{C}$; IR (ATR) v / $\mathrm{cm}^{-1} 3078(=\mathrm{C}-\mathrm{H})$, $1660(\mathrm{C}=\mathrm{O}), 1554(\mathrm{C}=\mathrm{N}), 1495(\mathrm{C}-\mathrm{N}), 820(\mathrm{C}-\mathrm{Cl}), 625$ $(\mathrm{C}-\mathrm{S}) ;{ }^{1} \mathrm{H}$ NMR $\left(400 \mathrm{MHz}, \mathrm{CDCl}_{3}\right) \delta 6.24(\mathrm{~s}, 1 \mathrm{H}), 4.47(\mathrm{t}$, $J 7.9 \mathrm{~Hz}, 2 \mathrm{H}), 3.51(\mathrm{t}, J 7.9 \mathrm{~Hz}, 2 \mathrm{H}) ;{ }^{13} \mathrm{C}$ NMR $(100 \mathrm{MHz}$, $\left.\mathrm{CDCl}_{3}\right) \delta 165.8,159.8,158.5,108.1,48.6,26.6$; EI-MS

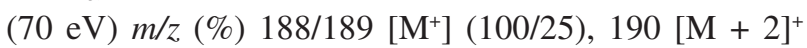
(37.7), $192[\mathrm{M}+4]^{+}(1.7)$; anal. calcd. for $\mathrm{C}_{6} \mathrm{H}_{5} \mathrm{ClN}_{2} \mathrm{OS}$ : C 38.21, H 2.67, N 14.85; found: C 38.03, H 2.67, N 14.45.

\section{Spectroscopic analysis}

Solution ${ }^{1} \mathrm{H}$ NMR $(400 \mathrm{MHz})$ spectra were recorded with a Bruker UltraShield spectrometer at $25^{\circ} \mathrm{C}$, using $\mathrm{CDCl}_{3}$. Chemical shifts were quoted in ppm relative to the residual solvent peak as reference. The following notation is used for the ${ }^{1} \mathrm{H}$ NMR spectral splitting patterns: 
singlet (s), doublet (d), triplet (t). The elemental analyses were obtained using a Thermo Scientific FlashEA 1112 elemental analyser. UV-Vis spectra were recorded on a Shimadzu UV-1700 PharmaSpec spectrophotometer. Fourier transform infrared (FTIR) spectra were taken in a Shimadzu FTIR-8400 spectrometer.

\section{Electrochemical analysis}

The electrochemical experiments were carried out in a $0.1 \mathrm{M}$ solution of $\mathrm{NBu}_{4} \mathrm{PF}_{6}$ in DMF in a classical threeelectrode cell, on an Autolab PGSTAT302N potentiostat/ galvanostat. The working electrode was a glassy carbon disc ( $3 \mathrm{~mm}$ diameter), the auxiliary electrode a platinum wire, the reference electrode a silver wire, and ferrocene was used as an internal standard at the end of the experiments. The measurements were carried out by cyclic and square wave voltammetries, and conducted at room temperature. In all cases, before the measurements the samples were degassed during 5 min using a controlled flow of nitrogen.

\section{Single crystal X-ray diffraction (SCXRD)}

Single crystal X-ray data for 7-chloro-2,3-dihydro$5 H$-thiazolo[3,2-a]pyrimidin-5-one (4) were collected on a Bruker D8 Venture diffractometer using $\mathrm{CuK} \alpha$ radiation (1.54178 ̊) monochromated by graphite. The cell determination and the final cell parameters were obtained on all reflections using the software Bruker SAINT $^{24}$ included in APEX2 software suite. Data integration and scaling was carried out using the software Bruker SAINT. ${ }^{24}$

Using Olex 2,25 the structure was solved with SHELXT ${ }^{26}$ structure solution program using intrinsic phasing, and the obtained model was refined by full-matrix least squares on $\mathrm{F}^{2}$ (SHELXL). ${ }^{27}$ All hydrogen atoms were placed in calculated positions and refined with fixed individual displacement parameters $\left[\mathrm{U}_{\mathrm{iso}}(\mathrm{H})=1.2\right.$ or $\left.1.5 \mathrm{U}_{\mathrm{eq}}\right]$, $\mathrm{U}_{\text {iso }}$ : isotropic thermal displacement parameter and, $\mathrm{U}_{\mathrm{eq}}$ : equivalent isotropic thermal displacement. The isotropic displacement parameter is coupled to one of the $\mathrm{C}$ atoms, having the 1.2- or 1.5-fold value, according to the riding model. Molecular representations, tables and pictures were generated by Platon, ${ }^{28}$ Diamond ${ }^{29}$ and Mercury. ${ }^{30}$ The crystal structure was deposited in the Cambridge Crystallographic Data Centre (CCDC), see SI section.

\section{Supplementary Information}

Crystallographic data (excluding structure factors) for the structures in this work were deposited in the
Cambridge Crystallographic Data Centre as supplementary publication number CCDC 1864395. Copies of the data can be obtained, free of charge, via www.ccdc. cam.ac.uk/conts/retrieving.html or from the Cambridge Crystallographic Data Centre, CCDC, 12 Union Road, Cambridge CB2 1EZ, UK; fax: +44 1223 336033. E-mail: deposit@ccdc.cam.ac.uk.

Supplementary information $\left({ }^{1} \mathrm{H}\right.$ and ${ }^{13} \mathrm{C}$ NMR spectra, Hirshfeld surface and 2D fingerprint plot for the compound HIXRUB and X-ray crystallographic data (CIF)) is available free of charge at http://jbcs.sbq.org.br as PDF file.

\section{Acknowledgments}

C. C. C.-V. and M. N. C. are grateful to the Vicerrectoría de Investigaciones and the Centro de Excelencia en Nuevos Materiales (CENM) from the Universidad del Valle (Colombia) for their generous financial support. Also, contributions from El Departamento Administrativo de Ciencia, Tecnología e Innovación (COLCIENCIAS) for the "Jovenes investigadores para la Paz" special grant No. FP44842-407-2017 are appreciated. R. F. D. acknowledges Direccion General de Investigaciones (DGI-USC) for the support. J. E. acknowledges the Brazilian funding agencies CAPES and FAPESP. The authors would also like to thank Dr Natalia Alvarez (Universidad de la Republica) for allowing access to the single crystal X-ray equipment.

\section{References}

1. Davidson, D.; Welo, L. A.; J. Phys. Chem. 1928, 32, 1191.

2. Perkin, W. H.; J. Chem. Soc., Trans. 1879, 35, 717.

3. Rulev, A. Y.; New J. Chem. 2017, 41, 4262.

4. Shirakawa, H.; Louis, E. J.; MacDiarmid, A. G.; Chiang, C. K.; Heeger, A. J.; J. Chem. Soc., Chem. Commun. 1977, 578.

5. Nicolaou, K. C.; Zhong, Y.-L.; Baran, P. S.; Angew. Chem., Int. Ed. 2000, 39, 622.

6. Basso, A.; Banfi, L.; Galatini, A.; Guanti, G.; Rastrelli, F.; Riva, R.; Org. Lett. 2009, 11, 4068.

7. Corcoran, E. B.; Pirnot, M. T.; Lin, S.; Dreher, S. D.; Dirocco, D. A.; Davies, I. W.; Buchwald, S. L.; MacMillan, D. W. C.; Science 2016, 353, 279.

8. Ghorab, M. M.; El-Batal, A. I.; Boll. Chim. Farm. 2002, 141, 110.

9. Fatima, S.; Sharma, A.; Saxena, R.; Tripathi, R.; Shukla, S. K.; Pandey, S. K.; Tripathi, R.; Tripathi, R. P.; Eur. J. Med. Chem. 2012, 55, 195.

10. Ismail, M. M. F.; El-Sayed, N. A. M.; Rateb, H. S.; Ellithey, M.; Ammar, Y. A.; Arzneim. Forsch. 2006, 56, 3.

11. Tozkoparan, B.; Ertan, M.; Kelicen, P.; Demirdamar, R.; Farmaco 1999, 54, 588. 
12. Sayed, H. H.; Shamroukh, A. H.; Rashad, A. E.; Acta Pharm. 2006, 56, 231.

13. Babu, K. R.; Rao, V. K.; Kumar, Y. N.; Polireddy, K.; Subbaiah, K. V.; Bhaskar, M.; Lokanatha, V.; Raju, C. N.; Antiviral Res. 2012, 95, 118.

14. Panneerselvam, T.; Karthick, V.; Kumar, P. V.; Ali, M. A.; Drug Discoveries Ther. 2012, 6, 198.

15. Roma, G.; Cinone, N.; Di Braccio, M.; Grossi, G.; Leoncini, G.; Signorello, M. G.; Carotti, A.; Bioorg. Med. Chem. 2000, 8,751 .

16. Clennon, R.; J. Heterocycl. Chem. 1979, 16, 903.

17. McKinnon, J. J.; Spackman, M. A.; Mitchell, A. S.; Acta Crystallogr., Sect. B: Struct. Sci. 2004, 60, 627.

18. Martin, A. D.; Britton, J.; Easun, T. L.; Blake, A. J.; Lewis, W.; Schröder, M.; Cryst. Growth Des. 2015, 15, 1697.

19. D’Vries, R. F.; Moreno-Fuquen, R.; Camps, I.; Ayala, A. P.; Kennedy, A. R.; Reinheimer, E. W.; Ellena, J.; CrystEngComm 2017, 19, 3753.

20. Romero, E. L.; Soto-Monsalve, M.; Gutiérrez, G.; Zuluaga, F.; D’Vries, R.; Chaur, M. N.; Rev. Colomb. Quim. 2018, 47, 63.

21. Low, J. N.; Ferguson, G.; Melguizo, M.; Sánchez, A.; Acta Crystallogr., Sect. C: Cryst. Struct. Commun. 1999, 55, IUC9900048.

22. Liu, X.; Zhou, J.; Yu, T.; Chen, C.; Cheng, Q.; Sengupta, K.; Huang, Y.; Li, H.; Liu, C.; Wang, Y.; Posocco, P.; Wang, M.; Cui, Q.; Giorgio, S.; Fermeglia, M.; Qu, F.; Pricl, S.; Shi, Y.;
Liang, Z.; Rocchi, P.; Rossi, J. J.; Peng, L.; Angew. Chem., Int. Ed. 2014, 53, 11822.

23. Lee, S. K.; Park, M. K.; Jhang, H. E.; Yi, J.; Nahm, K.; Cho, D. W.; Ra, C. S.; Musilek, K.; Horova, A.; Korabecny, J.; Dolezal, R.; Jun, D.; Kuca, K. K.; Bull. Korean Chem. Soc. 2015, 36, 1654.

24. Bruker SAINT; Bruker AXS Inc., Madison, Wisconsin, USA, 2012.

25. Dolomanov, O. V.; Bourhis, L. J.; Gildea, R. J.; Howard, J. A. K.; Puschmann, H.; J. Appl. Crystallogr. 2009, 42, 339.

26. Sheldrick, G. M.; Acta Crystallogr, Sect. A: Found. Crystallogr. 2015, $A 71,3$.

27. Sheldrick, G. M.; Acta Crystallogr., Sect. C: Cryst. Struct. Commun. 2015, 71, 3.

28. Spek, A. L.; Acta Crystallogr., Sect. D: Biol. Crystallogr. 2009, 65, 148.

29. Brandenburg, K.; Putz, H.; Diamond: Crystal and Molecular Structure Visualization software; Crystal Impact, Germany, 2006.

30. Macrae, C. F.; Edgington, P. R.; McCabe, P.; Pidcock, E.; Shields, G. P.; Taylor, R.; Towler, M.; van de Streek, J.; J. Appl. Crystallogr. 2006, 39, 453.

Submitted: September 20, 2018

Published online: March 19, 2019 